\title{
Contrast-Enhanced Ultrasound-Guided Prostate Biopsy
}

National Cancer Institute

\section{Source}

National Cancer Institute. Contrast-Enhanced UItrasound-Guided Prostate Biopsy. NCI

Thesaurus. Code C116511.

A radiologic technique that employs contrast agents to enable a more precise needle placement during a biopsy of the prostate. 